Article

\title{
Mandible Integrity and Material Properties of the Periodontal Ligament during Orthodontic Tooth Movement: A Finite-Element Study
}

\author{
Heng-Li Huang ${ }^{1,2,+}{ }^{\text {, Ming-Tzu Tsai }}{ }^{3,+}{ }^{\text {, Shih-Guang Yang }}{ }^{4}$, Kuo-Chih Su ${ }^{3,5}$, Yen-Wen Shen ${ }^{1,6}$ \\ and Jui-Ting Hsu 1,2,* \\ 1 School of Dentistry, College of Medicine, China Medical University, Taichung 404, Taiwan; \\ hlhuang@mail.cmu.edu.tw (H.-L.H.); a2312830@ms28.hinet.net (Y.-W.S.) \\ 2 Department of Bioinformatics and Medical Engineering, Asia University. Taichung 413, Taiwan \\ 3 Department of Biomedical Engineering, Hungkuang University, Taichung 433, Taiwan; \\ anniemtt@sunrise.hk.edu.tw (M.-T.T.); kcsu@vghtc.gov.tw (K.-C.S.) \\ 4 Master Program for Biomedical Engineering, China Medical University, Taichung 404, Taiwan; \\ cathikari33@gmail.com \\ 5 Department of Medical Research, Taichung Veterans General Hospital, Taichung 407, Taiwan \\ 6 Department of Dentistry, China Medical University and Hospital, Taichung 404, Taiwan \\ * Correspondence: jtsu@mail.cmu.edu.tw \\ + These authors contributed equally to this work.
}

Received: 31 March 2020; Accepted: 22 April 2020; Published: 24 April 2020 updates

\begin{abstract}
We used the finite-element method (FEM) to investigate the effects of jawbone model integrity and the material properties of the periodontal ligament (PDL) on orthodontic tooth movement. Medical imaging software and computer-aided design software were used to create finite-element models of a partial and complete mandibles based on dental cone beam computed tomography images of the human skull. Additionally, we exerted an orthodontic force on the canine crown in the direction of an orthodontic miniscrew under a lower molar root to compare the von Mises strain on the canine PDL in three models: a partial mandible model under orthodontic force (Model 1), a complete mandible model under orthodontic force (Model 2), and a complete mandible model under orthodontic force with clench occlusion in the intercuspal position (ICP; Model 3). Additionally, in the complete mandible model under orthodontic force with ICP occlusion, we analyzed the effects of a PDL with a low (Model 4), moderate (Model 5), and high (Model 6) linear elastic modulus and a PDL a bilinear elastic modulus (Model 7). The simulation results for mandible integrity indicated that the maximum von Mises strains on the canine PDL for Models 1, 2, and 3 were 0.461, 0.394, and 1.811, respectively. Moreover, for the models with different PDL material properties, the maximum von Mises strains on the canine PDLs for Models 4, 5, 6, and 7 were 6.047, 2.594, 0.887, and 1.811, respectively. When the FEM was used to evaluate tooth movement caused by orthodontic force, the transformation of a complete mandible model into a partial mandible model or alteration of the elastic modulus of the PDL influenced the biomechanical responses of the PDL. Additionally, the incorporation of daily ICP occlusion resulted in a larger effect.
\end{abstract}

Keywords: finite-element method; orthodontic; periodontal ligament; mandible

\section{Introduction}

Over the past 40 years, the finite-element method (FEM) has been widely used to study biomechanics in the fields of orthopedics and dentistry. Finite-element models enable researchers to understand data, such as the distribution of stress and strain, that are difficult to record using 
measurement devices. The FEM is widely used in dentistry for the research and development of artificial implants and surgical instruments, prediction of jawbone growth and developmental behaviors, orthodontic treatment or oral surgery, and preoperative and postoperative evaluations $[1,2]$. According to pressure-tension theory [3-6] in orthodontics, tooth movement is mainly caused by the biomechanical response of the periodontal ligament (PDL) surrounding the tooth. An orthodontic bracket exerts force on a tooth to compress or stretch the PDL. Previous studies have indicated that bone resorption and apposition are required in the compression and tension zones, respectively [3-6]. In other words, tooth movement is achieved through bone remodeling [3-6]. Finite-element modeling of the jawbone and orthodontic force can be used to evaluate changes in the stress, strain, and hydrostatic pressure of the PDL surrounding the tooth. In coordination with pressure-tension theory, FEM can be used to predict tooth movement and movement direction.

In the literature, FEM has been used for models with a single tooth [7-9], partial jawbone models with several teeth [10-12], and complete jawbone models with all teeth [13-16]. Additionally, these finite-element models have been used to explore the effects of the design and material properties of different orthodontic forces, brackets, and archwires on the biomechanical responses of the PDL during tooth movement. In studies that have employed the FEM to analyze such biomechanical responses, the assumed material properties of the PDL have affected the simulation results. Some studies have assumed that the PDL is a linear elastic material [10,11,17-20], but animal and cadaver studies [21-24] have indicated that the actual PDL is more similar to a bilinear elastic material. Other researchers have assumed that the PDL is a bilinear elastic material for conducting FEM simulations of biomechanical responses in tooth movement [25-28].

Numerous researchers have used FEM to analyze the biomechanical responses of the PDL during tooth movement due to orthodontic treatment. However, most of these studies have developed partial jawbone models with several teeth and used orthodontic force only as a loading condition. Therefore, in the present study, we evaluated the effect of partial and complete mandible models on the biomechanical responses of the PDL with and without occlusal force. Additionally, we discuss the determination of the material properties of the PDL by using a finite-element model.

\section{Materials and Methods}

\subsection{Geometry of the Finite-Element Model}

Two finite-element models were employed in this study, namely a partial mandible model and a complete mandible model. The complete mandibular model included the cortical and cancellous bones, all teeth except the first premolar, and the PDLs for all teeth except for the first premolar. A bracket was fixed to a canine crown, and an orthodontic miniscrew was placed between the first and second molar roots. The partial mandible model included the jawbone from the right mandibular lateral incisor to the second molar. Similar to the complete mandibular model, the partial mandibular model included the cortical bone, cancellous bone, the PDL, an orthodontic bracket, and a miniscrew. For both the partial and complete mandible models, the contours of the cortical bone, cancellous bone, and teeth were added to a dental cone beam computed tomography image of a human skull by using Mimics 15.0 (Materialise, Leuven, Belgium) before the image was segmented and saved in stereolithography (STL) format. Subsequently, the STL file was input into Geomagic Design X (3D Systems, ICP, Rock Hill, SC, USA) and transformed into a solid model. Since the PDL was excessively thin, we expanded the tooth model by $0.25 \mathrm{~mm}$ and performed a Boolean operation with the teeth and mandible to obtain a solid PDL model. Subsequently, we used SolidWorks (Swanson Analysis, Canonsburg, PA, USA) to illustrate the brackets and miniscrews (Figure 1). Finally, the finite-element package of ANSYS Workbench (Swanson Analysis, Canonsburg, PA, USA) was used to establish the material properties, meshing, boundary conditions, and loading conditions for all components of the solid model, thereby enabling the development of solutions. The numbers of elements and nodes in the partial mandible model were 44,827 and 71,548 , respectively. The numbers of elements and nodes in the complete 
mandible model were 151,296 and 235,603, respectively. The interfaces between the model components were assumed to have perfect bonding.

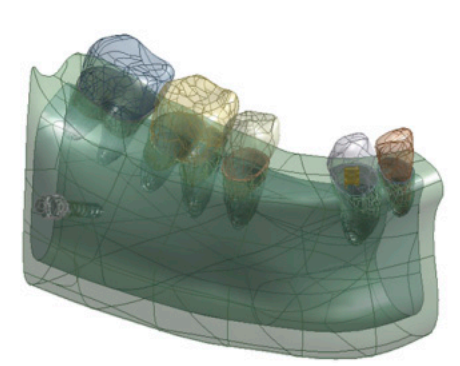

(a)

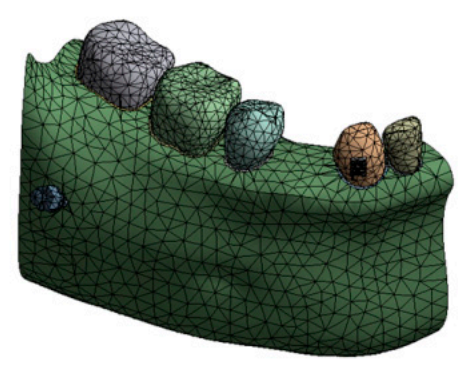

(c)
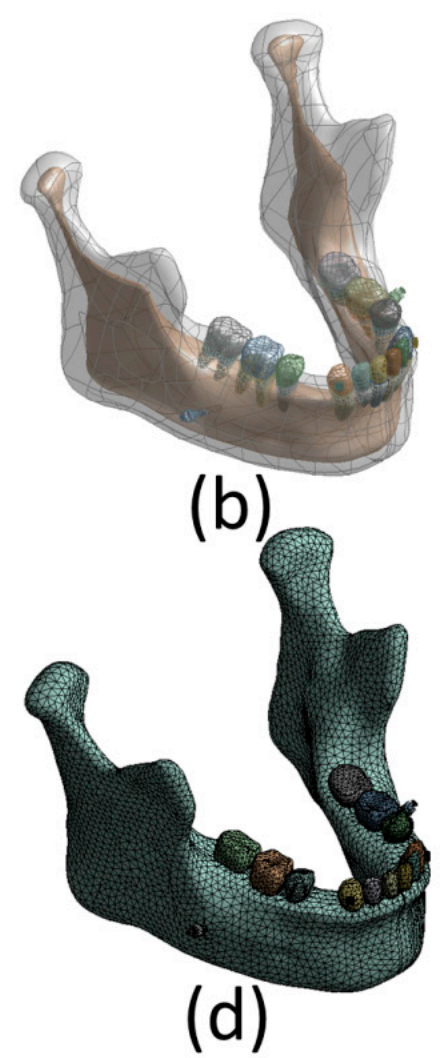

Figure 1. (a,b) Solid and (c,d) finite-element mesh models: $(\mathbf{a}, \mathbf{c})$ partial mandible and $(\mathbf{b}, \mathbf{d})$ complete mandible.

\subsection{Material Properties of the Finite-Element Model}

In addition to analyzing the effect of jawbone integrity on the finite-element model, we explored the effects of PDL material properties on biomechanical responses. We used four material settings for the PDL, namely three linear elastic materials and one bilinear elastic material, in accordance with previous studies. The material property settings are presented in Table 1.

Table 1. Material properties used in finite-element models.

\begin{tabular}{ccccc}
\hline Component & $\begin{array}{c}\text { Elastic Modulus } \\
\text { (MPa) }\end{array}$ & Poisson's Ratio & Reference \\
\hline Bracket & 230000 & 0.3 & Wu et al., 2011 [29] \\
Miniscrew & 14900 & 0.3 & Poppe et al., 2002 [22] \\
Cortical bone & 460 & 0.3 & Leung et al., 2008 [30] \\
Cancellous bone & 18600 & 0.3 & Cattaneo et al., 2005 [31] \\
& Tooth & 0.044 & 0.45 & Cattaneo et al., 2005 [31] \\
& Low linear elastic & 0.17 & 0.45 & Salehi et al., 2015 [20] \\
Middle linear elastic & 0.68 & 0.45 & Kawarizadeh et al., [21] \\
& High linear elastic & Poppe et al., 2002 [22] & \\
\hline
\end{tabular}




\subsection{Loading and Boundary Conditions}

As done previously $[11,18,25]$, we constrained the mesial and distal sides of the partial mandible model as boundary conditions. Additionally, we applied a loading condition of $2 \mathrm{~N}$ to simulate orthodontic force between the bracket and the miniscrew (Figure 2). For the complete mandible model, we used two sets of boundary and loading conditions. One model did not use occlusal force and simulated only $2 \mathrm{~N}$ of orthodontic force. To establish the boundary condition, this model was fully fixed at the top of the condyle. The second complete mandible model simulated an orthodontic force of $2 \mathrm{~N}$ in the intercuspal position (ICP) occlusion mode (Table 2.). In a previous study [32], a model was employed to stimulate the force of six muscles, namely the superficial masseter, deep masseter, medial pterygoid, anterior temporalis, middle temporalis, and posterior temporalis. Force was exerted on the mandible to achieve ICP occlusion. In addition to completely fixing the model at the top of the condyle, we considered the ICP occlusal mode by completely constraining the top of the incisal crown as a boundary condition (Figure 2).

Table 2. Muscular force and constraints in the intercuspal position (ICP) occlusal mode. Raw data were obtained from Korioth and Hannam [32].

\begin{tabular}{ccccccccc}
\hline \multirow{2}{*}{ Occlusal Mode } & \multirow{2}{*}{ Side } & \multirow{2}{*}{ Direction } & \multicolumn{7}{c}{ Muscular Force (N) } \\
\cline { 3 - 8 } & & & SM & DM & MP & AT & MT & PT \\
\hline \multirow{3}{*}{ Right } & Force & 76.2 & 21.2 & 136.3 & 12.6 & 5.7 & 3.0 \\
\cline { 3 - 8 } & & $\mathrm{F}_{X}$ & -15.8 & -11.6 & 66.3 & -1.9 & -1.3 & -0.6 \\
Intercuspal & & $\mathrm{F}_{Y}$ & -31.9 & 7.6 & -50.9 & -0.6 & 2.9 & 2.6 \\
position (ICP) & $\mathrm{F}_{Z}$ & 67.3 & 16.1 & 107.8 & 12.5 & 4.8 & 1.4 \\
\cline { 3 - 8 } & & Force & 76.2 & 21.2 & 136.3 & 12.6 & 5.7 & 3.0 \\
\cline { 3 - 8 } & \multirow{2}{*}{ Left } & $\mathrm{F}_{X}$ & 15.8 & 11.6 & -66.3 & 1.9 & 1.3 & 0.6 \\
& & $\mathrm{~F}_{Y}$ & -31.9 & 7.6 & -50.9 & -0.6 & 2.9 & 2.6 \\
& & $\mathrm{~F}_{Z}$ & 67.3 & 16.1 & 107.8 & 12.5 & 4.8 & 1.4 \\
\hline
\end{tabular}

Muscles: SM, superficial masseter; DM, deep masseter, MP, medial pterygoid; AT, anterior temporalis; MT, middle temporalis; $\mathrm{PT}$, posterior temporalis.

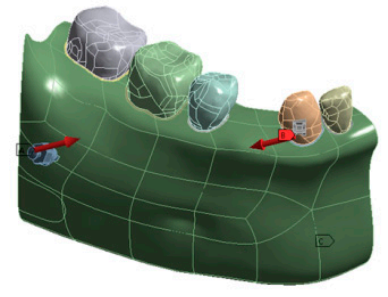

(a)

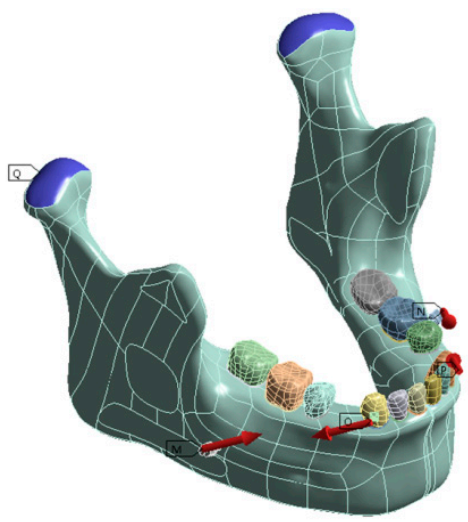

(b)

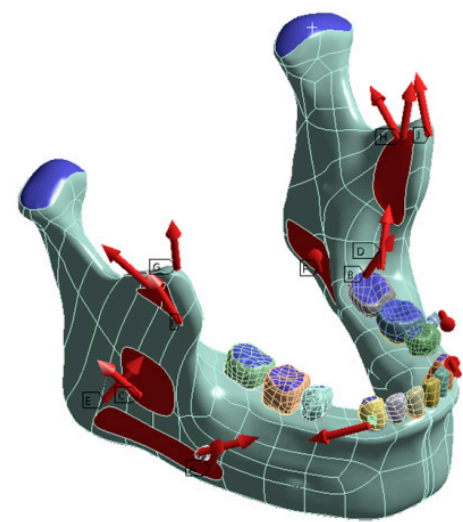

(c)

Figure 2. Loading and boundary conditions in finite-element simulations. (a) Partial mandible model under orthodontic force. (b) Complete mandible model under orthodontic force. (c) Complete mandible model under orthodontic force with ICP occlusion.

\subsection{Evaluation Parameters}

In this study, finite-element simulations were performed to analyze the integrity of the jawbone model and the effect of material property settings on the biomechanical responses of the PDL. Table 3 lists the finite-element simulation groups for these two aspects. Tooth movement is mainly caused by 
the biomechanical responses of the PDL surrounding the tooth. Therefore, in accordance with relevant studies [27,31], we evaluated the effect of von Mises stress and von Mises strain on the cortical and cancellous bones near the canine tooth by using the von Mises strain on the PDL as an indicator.

The definition of von Mises stress is $\left.\sigma_{\text {von }}=\sqrt{\frac{1}{2}\left[\left(\sigma_{1}-\sigma_{2}\right)^{2}+\left(\sigma_{1}-\sigma_{3}\right)^{2}+\left(\sigma_{2}-\sigma_{3}\right)^{2}\right.}\right]$, where $\sigma_{1}$, $\sigma_{2}$, and $\sigma_{3}$ are the principal stresses of the three different axes; that of von Mises strain is $\varepsilon_{\text {von }}=$ $\frac{1}{1+v^{\prime}} \sqrt{\frac{1}{2}\left[\left(\varepsilon_{1}-\varepsilon_{2}\right)^{2}+\left(\varepsilon_{2}-\varepsilon_{3}\right)^{2}+\left(\varepsilon_{3}-\varepsilon_{1}\right)^{2}\right]}$, where in $\varepsilon_{1}, \varepsilon_{2}$, and $\varepsilon_{3}$ are the principal strains of the three axes and $v^{\prime}$ is Poisson's ratio.

Table 3. Finite-element models used in this study.

\begin{tabular}{|c|c|c|c|c|c|c|c|}
\hline \multirow[b]{2}{*}{ Model No. } & \multicolumn{3}{|c|}{ Investigated issue: Integrity of mandible } & \multicolumn{4}{|c|}{ Investigated issue: Material property of PDL } \\
\hline & Model 1 & Model 2 & Model 3 & Model 4 & Model 5 & Model 6 & Model 7 \\
\hline $\begin{array}{l}\text { Mandibular } \\
\text { bone }\end{array}$ & $\begin{array}{c}\text { Partial } \\
\text { mandible }\end{array}$ & & & Complete $\mathrm{m}$ & ndible & & \\
\hline $\begin{array}{l}\text { Material } \\
\text { property of } \\
\text { PDL }\end{array}$ & \multicolumn{2}{|c|}{ Bilinear elastic } & & $\begin{array}{l}\text { Low linear } \\
\text { elastic }\end{array}$ & $\begin{array}{l}\text { Middle } \\
\text { linear } \\
\text { elastic }\end{array}$ & $\begin{array}{l}\text { High } \\
\text { linear } \\
\text { elastic }\end{array}$ & $\begin{array}{l}\text { Bilinear } \\
\text { elastic }\end{array}$ \\
\hline $\begin{array}{l}\text { Loading } \\
\text { condition }\end{array}$ & \multicolumn{2}{|c|}{ Orthodontic force } & \multicolumn{5}{|c|}{ Orthodontic force and ICP occlusal force } \\
\hline $\begin{array}{l}\text { Boundary } \\
\text { condition }\end{array}$ & $\begin{array}{l}\text { Constrained } \\
\text { the distal and } \\
\text { missal side of } \\
\text { partial } \\
\text { mandible }\end{array}$ & $\begin{array}{c}\text { Constrained } \\
\text { the top of } \\
\text { condyle }\end{array}$ & \multicolumn{5}{|c|}{ Constrained the top of the condyle and incisor regions } \\
\hline
\end{tabular}

\section{Results}

\subsection{Effect of Mandibular Integrity on the Simulation Results}

The maximum von Mises strains on the canine PDL in the partial mandible model under orthodontic force (Model 1), complete mandible model under orthodontic force (Model 2), and complete mandible model under orthodontic with ICP occlusal force (Model 3) were 0.461, 0.394, and 1.811, respectively (Figure 3). These data indicated a difference of $17 \%$ between Models 1 and 2. However, this difference was more apparent when ICP occlusal force was considered (Model 3). The maximum von Mises strains on the canine PDL in the partial (Model 1) and complete (Model 2) mandible models with only orthodontic force were merely $25.5 \%$ and $21.8 \%$ higher, respectively, than that in the complete mandible model under orthodontic force with ICP occlusal force (Model 3).

\subsection{Effect of PDL Material Properties on the Simulation Results}

When the PDL was assigned a low (Model 4), moderate (Model 5), and high (Model 6) linear elastic modulus and a bilinear elastic modulus (Model 7), the maximal von Mises strains on the canine tooth were 6.047, 2.594, 0.887, and 1.811, respectively (Figure 4). Models with low linear elastic modulus (Model 4) had higher von Mises strains because of the soft nature of the PDL. Moreover, the von Mises strain distributions were identical in the three PDL models with a linear elastic modulus (Models 4-6), with differences only in numerical values. However, when the PDL was set to have a bilinear elastic modulus (Model 7), the von Mises strain distribution differed slightly from those of the linear elastic PDL models (Figure 4). 

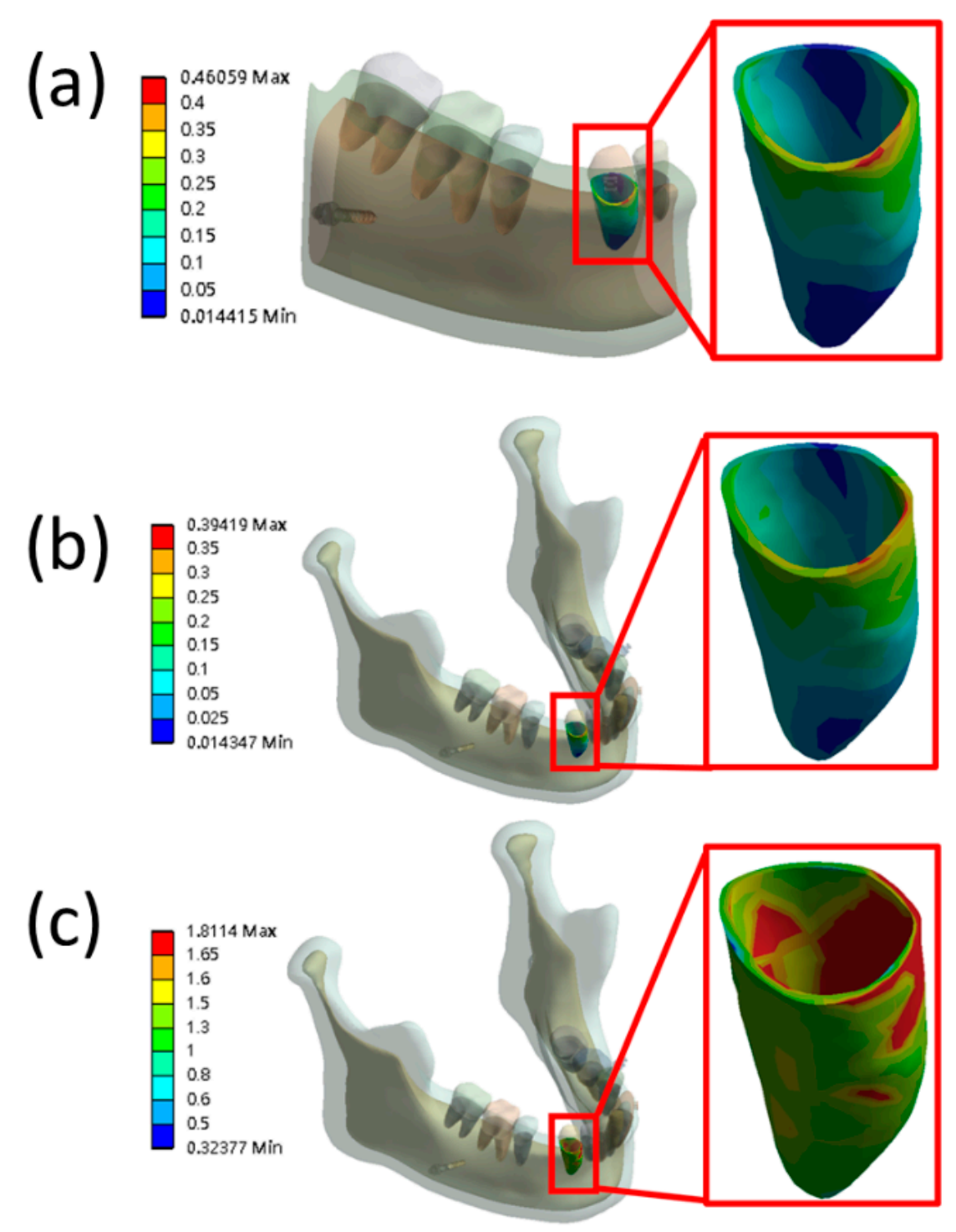

Figure 3. Distribution of von Mises strain in the canine periodontal ligament (PDL): (a) partial mandible model under orthodontic force; (b) complete mandible model under orthodontic force; and (c) complete mandible model under orthodontic force with ICP occlusal force.

\subsection{Effect of Mandibular Integrity and PDL Material Properties on Bone}

In addition to the effect of jawbone integrity on von Mises strain in the PDL, the effects of orthodontic force on von Mises stress in the cortical and cancellous bones near the canine PDL were negligible in the partial (Model 1) and complete (Model 2) mandible models. However, the simulation results of these models differed considerably from those of the complete mandible model under orthodontic and ICP occlusal forces (Model 3; Table 4). In addition, when the PDL was modeled with a bilinear elastic modulus (Model 7), the von Mises stresses in the cortical and cancellous bone were between those when the PDL was modeled with a low linear elastic modulus (Model 4) and high linear elastic modulus (Model 6; Table 4). 

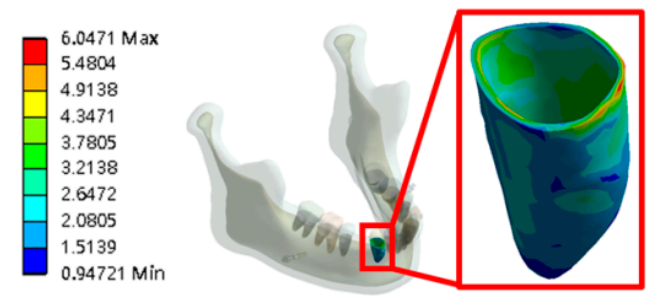

(a)
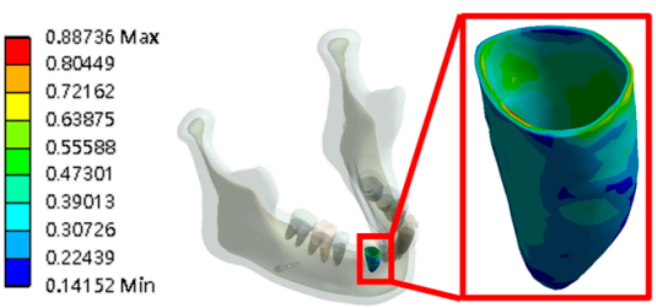

(c)
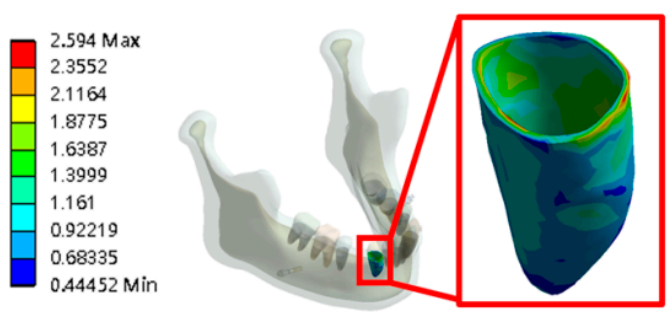

(b)
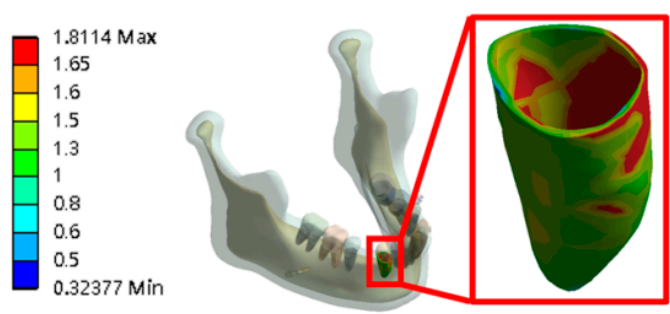

(d)

Figure 4. Distribution of von Mises strain in the canine PDL: models with (a) low linear elastic modulus, (b) moderate linear elastic modulus, (c) high linear elastic modulus, and (d) bilinear elastic modulus.

Table 4. Finite-element simulation results.

\begin{tabular}{cccccccc}
\hline & Investigated Issue: Integrity of Mandible & \multicolumn{4}{c}{ Investigated Issue: Material } \\
\hline & Model 1 & Model 2 & Model 3 & Model 4 & Model 5 & Model 6 & Model 7 \\
\hline $\begin{array}{c}\text { Max von Mises strain } \\
\text { on canine's PDL }\end{array}$ & 0.461 & 0.394 & 1.811 & 6.047 & 2.594 & 0.887 & 1.811 \\
\hline $\begin{array}{c}\text { Max von Mises stress } \\
\text { on cortical bone } \\
\text { around canine's PDL }\end{array}$ & 0.498 & 0.765 & 7.5375 & 6.25 & 8.3067 & 14.343 & 7.5375 \\
\hline $\begin{array}{c}\text { Max von Mises stress } \\
\text { on cancellous bone } \\
\text { around canine's PDL }\end{array}$ & 0.0599 & 0.0794 & 0.6914 & 0.5622 & 1.2387 & 1.5905 & 0.6914 \\
\hline
\end{tabular}

Unit of von Mises strain: None; Unit of von Mises stress: MPa.

\section{Discussion}

Numerous studies have used the FEM to analyze the biomechanical responses of the PDL during tooth movement due to orthodontic treatment. However, most such studies have used the FEM to develop partial jawbone models. The few studies that have created complete jawbone models have overlooked the occlusal force encountered in daily life. Therefore, we established partial and complete mandible models to analyze the effect of jawbone model integrity on the biomechanical reactions of the PDL by using the FEM. The simulation results suggested that the effects of the partial and complete mandible models on von Mises strain in the canine PDL were negligible when only orthodontic force was considered. However, the occlusal force that individuals exert in daily life had a substantial effect on the von Mises strain in the PDL. This effect was even larger when the PDL was assigned a linear elastic modulus.

The FEM is an excellent method for evaluating tooth movement caused by orthodontic treatment because it can simulate orthodontic forces of different amounts and directions. The biomechanical responses of the PDL can be evaluated, and the direction and rate of tooth movement can be predicted according to pressure-tension theory. Numerous researchers have used the FEM to investigate tooth movement during orthodontic treatment, but most studies have created only partial jawbone models. Although some studies have established complete jawbone models, their goals were to analyze the effects of occlusal modes on jawbone biomechanical response [32] or on the PDL [33]. However, 
whether occlusal force interferes with the mechanical response of the PDL during orthodontic treatment has remained unclear.

Our simulation results suggest that the maximum von Mises strains in the canine PDL differed by $17.0 \%$ between the partial and complete mandible models. This difference was caused by the difference in method used for setting the boundary conditions. The partial mandible model involves a finite-element simulation for the mesial and distal sides. The proximal side of the mandible near the side incisors was a fixed surface that was too close to the canine tooth and was moving in the distal direction. Therefore, when the canine PDL exerted orthodontic force against the mesial side, the strain distribution differed substantially from that in the complete mandible model, which was subject only to orthodontic force. The distal side of the canine PDL was farther from the completely fixed partial mandible mesial side. Thus, the effect on strain distribution was weaker. This demonstrates that boundary conditions should be applied farther from the tooth requiring movement in future models of tooth movement due to orthodontic treatment. In other words, for a partial mandible, a larger area must be modeled to mitigate effects on the simulation results. Moreover, our simulation results suggested that the maximum von Mises strain in the ICP occlusal mode was 4.6-times higher than that in the complete mandible model without ICP occlusion. Therefore, the occlusal force encountered in daily life had a considerable effect. However, during orthodontic treatment, the jawbone was not constantly subjected to occlusal force. This study only demonstrated that occlusal force could affect simulation results. Therefore, we recommend that the analysis of tooth movement caused by orthodontic force should incorporate occlusal force.

Numerous studies have assumed that the PDL is a linear elastic material [10,11,17-20]. However, the PDL is mainly composed of collagen fibers [34], and its material properties are more similar to those of a nonlinear elastic material. Numerous studies have directly measured PDL material properties, but relevant studies have suggested that the material properties of soft tissues are easily affected by freeze-thaw cycles at temperatures of $>20^{\circ} \mathrm{C}$ [35]. Unfrozen human cadaver jawbone specimens are unavailable, and experiments on most human cadaver bones or tooth specimens can only be conducted after a freeze-thaw cycle. Poppe et al. [22] and Liu et al. [24] have conducted mechanical experiments on mandibular fragments of human corpses to directly measure the elastic modulus of the PDL. Experimental results have suggested that the PDL is a bilinear elastic material. Kawarizadeh et al. [21] and Ziegler et al. [23] have measured the PDL elastic modulus in rat and miniature pig specimens and have also demonstrated that the PDL has bilinear elastic properties.

Our simulation results for the bilinear elastic PDL model differed from those for the linear elastic PDL model, which is in agreement with the findings of other studies [31,36]. When the PDL was assigned a low linear, moderate linear, high linear, and bilinear elastic modulus, the maximum von Mises strains on the canine PDL were 6.047, 2.594, 0.887, and 1.811, respectively. However, because of the limitations of the different finite-element models and methods of exerting orthodontic force, we were unable to conduct an absolute-value comparison between our simulation results and those of other studies. However, the simulation results suggested that strain was more concentrated in the PDL when the PDL was assumed to have a linear elastic modulus, and it was more evenly distributed when the PDL was assumed to have a bilinear elastic modulus.

Although we established a complete mandible model and simulated the ICP occlusal mode, this study had several limitations. First, orthodontic wire was not used in the finite-element model. Thus, friction between brackets and orthodontic wire was not considered. Second, bone is an inhomogeneous anisotropic tissue with a trabecular structure. In this study, bone had linear elastic, isotropic, and homogenous material properties, in accordance with those adopted in most relevant studies. Third, we simulated only the ICP occlusal mode; other occlusal modes may have different effects on the PDL.

\section{Conclusions}

When the FEM was employed to evaluate tooth movement due to orthodontic force, the biomechanical response of the PDL was affected by mandible integrity; thus the complete mandible 
model was converted into a partial mandible model. Furthermore, the incorporation of daily ICP occlusion resulted in a larger effect. In addition, assumptions regarding the material properties of the PDL affected the biomechanical response of the PDL.

Author Contributions: Conceptualization, H.-L.H., S.-G.Y. and J.-T.H.; methodology, S.-G.Y. and J.-T.H.; writing-original draft preparation, H.-L.H., Y.-W.S., M.-T.T., K.-C.S. and J.-T.H.; writing-M.-T.T. and J.-T.H. All authors have read and agreed to the published version of the manuscript.

Funding: This research was supported by Ministry of Science and Technology, Taiwan (Grant number: MOST 108-2221-E-039-004) and China Medical University, Taiwan (Grant number: CMU108-MF-86).

Conflicts of Interest: The authors declare no conflict of interest.

\section{References}

1. Hsu, M.-L.; Chang, C.-L. Application of Finite Element Analysis in Dentistry. Finite Elem. Anal. Sciyo 2010. [CrossRef]

2. Piccioni, M.A.R.; Campos, E.A.; Saad, J.R.C.; de Andrade, M.F.; Galvão, M.R.; Rached, A.A. Application of the finite element method in Dentistry. RSBO Rev. Sul-Bras. Odontol. 2013, 10, 369-377.

3. Cattaneo, P.; Dalstra, M.; Melsen, B. Strains in periodontal ligament and alveolar bone associated with orthodontic tooth movement analyzed by finite element. Orthod. Craniofacial Res. 2009, 12, 120-128. [CrossRef] [PubMed]

4. Chang, H.-W.; Huang, H.-L.; Yu, J.-H.; Hsu, J.-T.; Li, Y.-F.; Wu, Y.-F. Effects of orthodontic tooth movement on alveolar bone density. Clin. Oral Investig. 2012, 16, 679-688. [CrossRef] [PubMed]

5. Masella, R.S.; Meister, M. Current concepts in the biology of orthodontic tooth movement. Am. J. Orthod. Dentofac. Orthop. 2006, 129, 458-468. [CrossRef] [PubMed]

6. Will, L.A. Orthodontic Tooth Movement: A Historic Prospective. Front Oral Biol. 2016, 18, 46-55.

7. Tanne, K.; Sakuda, M.; Burstone, C.J. Three-dimensional finite element analysis for stress in the periodontal tissue by orthodontic forces. Am. J. Orthod. Dentofac. Orthop. 1987, 92, 499-505. [CrossRef]

8. Sardarian, A.; Shahidi, S.; Boushehri, S.G.; Geramy, A. The effect of vertical bracket positioning on torque and the resultant stress in the periodontal ligament-A finite element study. Prog. Orthod. 2014, 15, 50. [CrossRef]

9. Sugii, M.M.; Barreto, B.C.F.; Francisco Vieira-Junior, W.; Simone, K.R.I.; Bacchi, A.; Caldas, R.A. Extruded upper first molar intrusion: Comparison between unilateral and bilateral miniscrew anchorage. Dent. Press J. Orthod. 2018, 23, 63-70. [CrossRef]

10. Caballero, G.M.; de Carvalho Filho, O.A.; Hargreaves, B.O.; de Araújo Brito, H.H.; Junior, P.A.A.M.; Oliveira, D.D. Mandibular canine intrusion with the segmented arch technique: A finite element method study. Am. J. Orthod. Dentofac. Orthop. 2015, 147, 691-697. [CrossRef]

11. Field, C.; Ichim, I.; Swain, M.V.; Chan, E.; Darendeliler, M.A.; Li, W.; Li, Q. Mechanical responses to orthodontic loading: A 3-dimensional finite element multi-tooth model. Am. J. Orthod. Dentofac. Orthop. 2009, 135, 174-181. [CrossRef] [PubMed]

12. Gerami, A.; Dadgar, S.; Rakhshan, V.; Jannati, P.; Sobouti, F. Displacement and force distribution of splinted and tilted mandibular anterior teeth under occlusal loads: An in silico 3D finite element analysis. Prog. Orthod. 2016, 17, 16. [CrossRef] [PubMed]

13. Liao, Z.; Elekdag-Turk, S.; Turk, T.; Grove, J.; Dalci, O.; Chen, J.; Zheng, K.; Ali Darendeliler, M.; Swain, M.; $\mathrm{Li}, \mathrm{Q}$. Computational and clinical investigation on the role of mechanical vibration on orthodontic tooth movement. J. Biomech. 2017, 60, 57-64. [CrossRef] [PubMed]

14. Zhou, X.; Xia, Z.; Gan, Y.; Zhang, D.; Xiong, J.; Fang, P.; Li, G.; Zhao, Q. Orthodontic force simulation of Tooth-PDL-Bone Complex under archwire loading. In Proceedings of the 38th Annual International Conference of the IEEE Engineering in Medicine and Biology Society (EMBC), Lake Buena Vista, FL, USA, 16-20 August 2016; pp. 6030-6033.

15. Namburi, M.; Nagothu, S.; Kumar, C.S.; Chakrapani, N.; Hanumantharao, C.H.; Kumar, S.K. Evaluating the effects of consolidation on intrusion and retraction using temporary anchorage devices-A FEM study. Prog. Orthod. 2017, 18, 2. [CrossRef]

16. Chen, J.; Li, W.; Swain, M.V.; Ali Darendeliler, M.; Li, Q. A periodontal ligament driven remodeling algorithm for orthodontic tooth movement. J. Biomech. 2014, 47, 1689-1695. [CrossRef] 
17. Bouton, A.; Simon, Y.; Goussard, F.; Teresi, L.; Sansalone, V. New finite element study protocol: Clinical simulation of orthodontic tooth movement. Int. Orthod. 2017, 15, 165-179. [CrossRef]

18. de Souza, F.I.; Poi, W.R.; da Silva, V.F.; Martini, A.P.; Melo, R.A.; Panzarini, S.R.; Rocha, E.P. Stress distribution in delayed replanted teeth splinted with different orthodontic wires: A three-dimensional finite element analysis. Dent. Traumatol. 2015, 31, 190-195. [CrossRef]

19. McCormack, S.W.; Witzel, U.; Watson, P.J.; Fagan, M.J.; Groening, F. Inclusion of periodontal ligament fibres in mandibular finite element models leads to an increase in alveolar bone strains. PLoS ONE 2017, 12, e0188707. [CrossRef]

20. Salehi, P.; Gerami, A.; Najafi, A.; Torkan, S. Evaluating stress distribution pattern in periodontal ligament of maxillary incisors during intrusion assessed by the finite element method. J. Dent. 2015, 16, 314-322.

21. Kawarizadeh, A.; Bourauel, C.; Jäger, A. Experimental and numerical determination of initial tooth mobility and material properties of the periodontal ligament in rat molar specimens. Eur. J. Orthod. 2003, 25, 569-578. [CrossRef]

22. Poppe, M.; Bourauel, C.; Jäger, A. Determination of the elasticity parameters of the human periodontal ligament and the location of the center of resistance of single-rooted teeth a study of autopsy specimens and their conversion into finite element models. J. Orofac. Orthop. Fortschr. Kieferorthopädie 2002, 63, 358-370. [CrossRef] [PubMed]

23. Ziegler, A.; Keilig, L.; Kawarizadeh, A.; Jäger, A.; Bourauel, C. Numerical simulation of the biomechanical behaviour of multi-rooted teeth. Eur. J. Orthod. 2005, 27, 333-339. [CrossRef] [PubMed]

24. Liu, T.-C.; Chang, C.-H.; Wong, T.-Y.; Liu, J.-K. Finite element analysis of miniscrew implants used for orthodontic anchorage. Am. J. Orthod. Dentofac. Orthop. 2012, 141, 468-476. [CrossRef] [PubMed]

25. Hartmann, M.; Dirk, C.; Reimann, S.; Keilig, L.; Konermann, A.; Jager, A.; Bourauel, C. Influence of tooth dimension on the initial mobility based on plaster casts and X-ray images: A numerical study. J. Orofac. Orthop. 2017, 78, 285-292. [CrossRef]

26. Verna, C.; Cattaneo, P.M.; Dalstra, M. Corticotomy affects both the modus and magnitude of orthodontic tooth movement. Eur. J. Orthod. 2018, 40, 107-112. [CrossRef]

27. Papageorgiou, S.N.; Keilig, L.; Hasan, I.; Jäger, A.; Bourauel, C. Effect of material variation on the biomechanical behaviour of orthodontic fixed appliances: A finite element analysis. Eur. J. Orthod. 2016, 38, 300-307. [CrossRef]

28. Papageorgiou, S.N.; Keilig, L.; Vandevska-Radunovic, V.; Eliades, T.; Bourauel, C. Torque differences due to the material variation of the orthodontic appliance: A finite element study. Prog. Orthod. 2017, 18, 6. [CrossRef]

29. Wu, J.-H.; Wang, H.-C.; Chen, C.-M.; Lu, P.-C.; Lai, S.-T.; Lee, K.-T.; Du, J.-K. Pullout strengths of orthodontic palatal mini-implants tested in vitro. J. Dent. Sci. 2011, 6, 200-204. [CrossRef]

30. Leung, M.T.-C.; Lee, T.C.-K.; Rabie, A.B.M.; Wong, R.W.-K. Use of miniscrews and miniplates in orthodontics. J. Oral Maxillofac. Surg. 2008, 66, 1461-1466. [CrossRef]

31. Cattaneo, P.; Dalstra, M.; Melsen, B. The finite element method: A tool to study orthodontic tooth movement. J. Dent. Res. 2005, 84, 428-433. [CrossRef]

32. Korioth, T.; Hannam, A. Deformation of the human mandible during simulated tooth clenching. J. Dent. Res. 1994, 73, 56-66. [CrossRef] [PubMed]

33. Koolstra, J.; Van Eijden, T. Three-dimensional dynamical capabilities of the human masticatory muscles. J. Biomech. 1999, 32, 145-152. [CrossRef]

34. Pöschke, A.; Krähling, B.; Failing, K.; Staszyk, C. Molecular characteristics of the equine periodontal ligament. Front. Vet. Sci. 2018, 4, 235. [CrossRef] [PubMed]

35. Hongo, M.; Gay, R.E.; Hsu, J.-T.; Zhao, K.D.; Ilharreborde, B.; Berglund, L.J.; An, K.-N. Effect of multiple freeze-thaw cycles on intervertebral dynamic motion characteristics in the porcine lumbar spine. J. Biomech. 2008, 41, 916-920. [CrossRef] [PubMed]

36. Hemanth, M.; Deoli, S.; Raghuveer, H.; Rani, M.; Hegde, C.; Vedavathi, B. Stress induced in periodontal ligament under orthodontic loading (Part II): A comparison of linear versus non-linear FEM study. J. Int. Oral Health JIOH 2015, 7, 114-118. [PubMed]

(C) 2020 by the authors. Licensee MDPI, Basel, Switzerland. This article is an open access article distributed under the terms and conditions of the Creative Commons Attribution (CC BY) license (http://creativecommons.org/licenses/by/4.0/). 